\title{
Meningkatkan Hasil Belajar Sosiologi melalui Kardi Pinter
}

\author{
Ari Tri Noeryanti ${ }^{1}$ \\ buharyort3@gmail.com
}

\begin{abstract}
The pupose of this action research is help students to achive higher score and develop their character and ability to adapt and solve the problems. Kardi Pinter stands for cards, discussion and guided inqury. The teacher explain the material so that students can guess the material explained by teacher to have a correct understanding in terms that are introduced. Project assigment begin by looking at enviromental potential and create new innovations. Student projects assigments to obtain an analysis enhanced through joint project in a group by using RRA method : transect, social mapping, problem three analysis, foccused group discussion. Kardi Pinter learning outcomes generate enthusiasm in caring for environment and learning achievement significantly. Kardi Pinter has been able to improved students achievement to have complrtion value by $65 \%$. There fore replication of Kardi Pinter model learning is feasible to be done as a solution to improve student learning with the same conditions as class XII C.
\end{abstract}

Keywords: $\quad$ Cards, Discussion, Guided inquiry

Abstract: $\quad$ Tujuan dari penelitian tindakan ini adalah membantu siswa untuk mencapai skor yang lebih tinggi dan mengembangkan karakter dan kemampuan mereka untuk beradaptasi dan menyelesaikan masalah. Kardi Pinter adalah singkatan dari kartu, diskusi, dan inqury. Guru menjelaskan materi sehingga siswa dapat menebak materi yang dijelaskan oleh guru untuk memiliki pemahaman yang benar dalam hal yang diperkenalkan. Tugas proyek dimulai dengan melihat potensi lingkungan dan menciptakan inovasi baru. Pelajar memproyeksikan tugas untuk memperoleh analisis yang ditingkatkan melalui proyek bersama dalam sebuah kelompok dengan menggunakan metode RRA: transek, pemetaan sosial, analisis masalah tiga, diskusi kelompok terfokus. Hasil belajar Kardi Pinter menghasilkan antusiasme dalam merawat lingkungan dan prestasi belajar secara signifikan. Kardi Pinter telah mampu meningkatkan prestasi siswa untuk memiliki nilai pujian sebesar $65 \%$. Oleh karena itu replikasi pembelajaran model Kardi Pinter layak dilakukan sebagai solusi untuk meningkatkan pembelajaran siswa dengan kondisi yang sama dengan kelas XII C.

Kata Kunci: Kartu, Inkuiri terbimbing, Diskusi

$\begin{array}{llll}\text { Submitted: Februari } 2020 & \text { Reviewed: Maret } 2020 & \text { Accepted: Maret 2020 } & \text { Published: Maret 2020 }\end{array}$

1 Teknologi Pendidikan, Universitas Sebelas Maret 


\section{PENDAHULUAN}

$\mathrm{P}$ erkembangan teknologi informasi dan komunikasi demikian pesat dan telah mengubah tatanan kehidupan manusia saat ini. Dunia pendidikan dikritik lambat merespon perubahan ini dibandingkan dengan kalangan industri. Perubahaan dunia industri menciptakan produk dan jasa spesifik yang sesuai konsumen dari segmentasi generasi tersebut. Dunia pendidikan belum banyak meengembangkan karakterisik anak muda dari setiap generasi tersebut dalam perancangan kurikulum maupun proses pembelajaran. Padahal Generasi $Y$ yang lahir pada awal era digital sangat berbeda dibandingkan dengan Generasi Z yang lahir pada era digital (Sukmana, 2018). Konsep menteri milenial tentang merdeka belajar yang menginspirasi dunia pendidikan bahwa untuk belajar butuh ruang leluasa untuk berkarya tanpa sekat batas yang tidak perlu jika hanya sekedar formalitas. Misalnya guru dituntut untuk membuat rencana belajar yang memiliki pedoman yang ditentukan oleh berbagai kepentingan akibatnya untuk tugas administrasi bisa mencetak banyak yang menghabiskan banyak kertas. Guru dalam menjalankan pembelajaran seringkali tidak sesuai dengan urut-urutan tahap di perencana terkadang harus berinovasi untuk mensiasati kondisi lingkungan dan keberagaman siswa atau kurikulum yang tersembunyi (Wahyuni, 2018). Selain itu konsep merdeka belajar juga memberikan dukungan terhadap segala kesulitan guru baik teknis atau moril supaya guru dapat menolong dan memfasilitasi siswa dengan baik.

Guru merdeka juga dituntut untuk mengimplementasi penguatan pendidikan karakter (PPK) yang dibutuhkan untuk memenuhi kecakapan abad 21 (Aji, 2019). PPK merupakan solusi untuk menyiapkan generasi emas 2024 yang unggul di bidang intelektual, tangguh menghadapi masalah, cerdas untuk mencari solusi msalah dan berkarakter jujur, disipilin, suka gotong royong dan berintegritas. Platform PPK diarahkan membentuk generasi berjiwa Pancasila. Definisi PPK menurut Perpres nomor 87 tahun 2017 adalah Gerakan pendidikan dibawah tanggungjawab satuan pendidikan untuk memperkuat karakter peserta didik melalui harmonisasi olah hati, olah rasa, olah pikir dan olahraga dengan pelibatan dan kerjasama antara satuan pendidikan, keluarga dan masyarkat sebagai bagian dari "Gerakan Nasional Revolusi Mental (GNRM)" (Kemendikbud, 2018).

Merdeka belajar dan penguatan pendidikan karakter adalah dasar guru membuat dan merancang pembelajaran agar para peserta didik mendapatkan manfaat yang maksimal, yaitu karakter cerdas, tangguh, jujur, peduli, dan berintegritas. Fokus pendidikan karakter dalam beberapa langkah yang meliputi 1) konteks : situasi nyata di lapangan. 2) Refleksi : menyimak kembali pengalaman akan peristiwa yang dialami untuk memahami maknanya. 3) Repetisi : pengulangan adalah aspek penting dalam pendidikan, kebaikan harus diulang-ulang sehingga menjadi nilai dominan. 4) Aksi : tindakan yang dipilih sesuai dengan nilai - nilai karakter jujur, peduli, tangguh dan berintegritas. 5) evaluasi : adalah proses penilaian yang terencana, sistemik, terarah berdasarkan tujuan yang jelas sehingga mendapatkan kemajuan (Rismawati, Sinon \& Yusuf, 2017).

Fenomena abad 21 memiliki kecenderungan para peserta didik secara sosiologis tidak lagi interaksi sosial secara langsung, namun sudah menggunakan media sosial. Kecenderungan media sosial mendorong perilaku egois, tidak peduli orang lain, kurang empati, kurang simpati, kurang dapat bekerjasama dengan orang lain. Peserta didik banyak yang merasa jenuh dan bosan dengan literasi sosiologi yang bersifat konseptual dan abstrak. Masalah yang ditemukan pembelajaran sosiologi tidak hanya secara substansial namun juga metode dan strategi pembelajaran yang monoton (Setiadi, Elly \& Kolip, 2015). Kondisi peserta didik yang merupakan generasi milineal yang sangat egois dan tidak peduli lingkungan akibat zaman yang serba instan yang didukung oleh sikap hidup yang bergantung dengan gawai membuat masalah internal siswa susah untuk diintervensi supaya sadar akan sesama dan lingkungan (Aji, 2019). Hal tersebut merupakan tantangan yang harus dihadapi guru sosiologi yang harus diatasi. 
Oleh sebab itu dibutuhkan strategi dan model pembelajaran yang tepat agar generasi milineal yang egois dapat berinteraksi melalui pembelajaran kolaboratif, aktif dan langsung di lapangan sebagai solusi agar para siswa mampu mengatasi masalahnya dan masalah lingkungan secara sistematis dan terarah (Feriati, 2017). Maka dipilihlah pendekatan saintifik, model project-based learning yang dikombinasikan pembelajaran aktif menggunakan kartu dan diskusi ditambah pengalaman belajar di lapangan dengan metode RRA (rural rapid appraisal) karya Chambers. RRA yang dipilih adalah transect (jalan-jalan/observasi), social mapping (pemetaan sosial), problem tree analysis (analisa pohon masalah), Foccused group discussion (FGD) (Tahmidaten, 2016) yang secara simultan dialami supaya peserta didik dapat memahami sosiologi secara substansial, memaknainya,mengidentifikasi dan mengatasi masalah baik secara individu dan kelompok (Tahmidaten, 2016). Hal ini didukung oleh beberapa penelitian sebelumnya misalnya yang dilakukan Luthfi (2016) yang berjudul : Perbandingan Metode Pemberian Tugas Kerja Kelompok dengan Kerja Individu pada Model Pembelajaran Discovery Learning terhadap Hasil Belajar Peserta Didik Kelas XI MIA SMAN 1 Tondong Tallasa Kab.Pangkep (Studi pada Materi Pokok Termokimia). Hasil penelitian tersebut Perbandingan Metode Pemberian Tugas Kerja Kelompok dengan Kerja Individu pada Model Pembelajaran Discovery Learning terhadap Hasil Belajar Peserta Didik Kelas XI MIA SMAN 1 Tondong Tallasa Kab.Pangkep (Studi pada Materi Pokok Termokimia) Nilai sikap peduli dan toleransi kelas eksperimen I yaitu $84 \%$ dan $96,66 \%$ lebih tinggi dari kelas eksperimen II yaitu 80,49\% dan 93,33\%.

\section{METODE PENELITIAN}

Penelitian tindakan kelas adalah usaha reflektif guru (Faisal, 2015), ditujukan untuk memperdalam pemahaman terhadap tindakan yang dilakukan selama proses pembelajaran untuk mempelajari kelemahan - kelemahan yang masih terjadi dan melakukan upaya perbaikan guna mewujudkan tujuantujuan dalam proses pembelajaran (Yudistira, 2015). Jika proses perbaikan dilakaukan terus menerus diharapkan dapat mendatangkan manfaat sebaik-baiknya untuk menghadapi tantangan generasi milenial serta tantangan untuk melakukan pendidikan karakter yang dibutuhkan.

Penelitian kolaboratif dipilih karena memiliki tujuan sebagai berikut :

1. Memaksimalkan proses kerjasama yang berlangsung secara alamiah di antara para siswa.

2. Menciptakan lingkungan pembelajaran yang berpusat pada siswa, kontekstual, terintegrasi, dan bersuasana kerjasama.

3. Menghargai pentingnya keaslian, kontribusi, dan pengalaman siswa dalam kaitannya dengan bahan pelajaran dan proses belajar.

4. Memberi kesempatan kepada siswa menjadi partisipan aktif dalam proses belajar.

5. Mengembangkan berpikir kritis dan ketrampilan pemecahan masalah.

6. Mendorong eksplorasi bahan pelajaran yang melibatkan bermacam-macam sudut pandang.

7. Menghargai pentingnya konteks sosial bagi proses belajar.

8. Menumbuhkan hubungan yang saling mendukung dan saling menghargai di antara para siswa, dan di antara siswa dan guru.

9. Membangun semangat belajar sepanjang hayat.

Penelitian dilakukan di SMAN 1 Ngemplak Boyolali Jawa Tengah dipilih kelas XII IPS 2 atau XII IPS C yang jumlah 23 peserta didik. Mengapa kelas XII C karena peserta didik dianggap yang paling tidak disiplin, banyak melakukan pelanggaran tata tertib sekolah dan nilai hasil belajarnya rendah daripada kelas A dan B. Berdasarkan penelitian maka diperoleh adalah data numerik berasal dari nilai 
ulangan atau uji kompetensi peserta didik. Data kualitatif juga diperoleh atas dasar observasi kondisi sebelum metode Kardi Pinter digunakan dan setelah metode Kardi Pinter digunakan untuk melihat ekspresi, minat dan antusiasme peserta didik terhadap pembelajaran sosiologi.

\section{Siklus Pelaksanaan PTK}

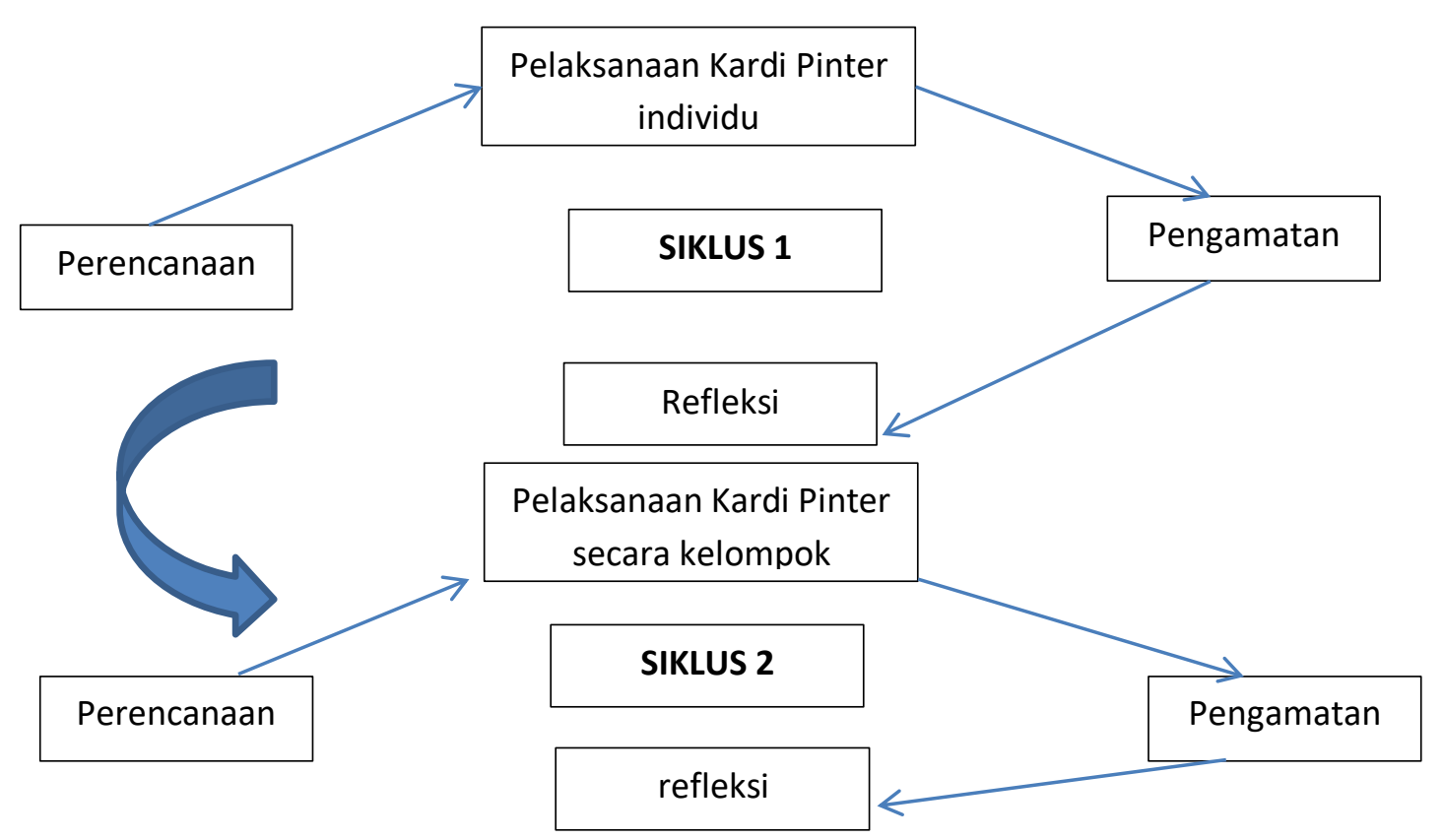

Gambar 1.Model Siklus Penelitian Tindakan Kelas Model John Elliot (Yudistira, 2015)

\section{SIKLUS PERTAMA}

Kardi Pinter merupakan kependekan dari kartu, diskusi dan inquiry terbimbing. Kombinasi pembelajaran aktif ( kartu, individu ) dan kolaboratif (project based learning). Pembelajaran sosiologi menggunakan Kardi Pinter pada langkah pertama melalui beberapa langkah, pertama peserta didik diberi materi penelitian sosial dengan mengenali kartu yang berisi istilah-istilah populer dalam materi penelitian sosial. Guru memberikan pertanyaan sedangkan siswa menebak kartu yang berisi istilah dalam penelitian sosial. Kedua peserta didik diberi proyek individu untuk membuat kreasi dari tahu. Mengapa tahu karena produk olahan kedelai ini merupakan hasil dari pengrajin tahu disekitas sekolah. Peserta didik akan presentasi di depan kelas dan mendiskusikan langkah-langkah yang dilakukan untuk mengetahui jenis-jenis olahan berbahan dasar tahu. Diskusi antar individu atas arahan dan bimbingan guru. Peserta didik kemudian diberi penugasan individual untuk melakukan observasi (jalan - jalan) atau transect, pemetaan masyarakat untuk mengetahui selera per kelas (social mapping), analisa sampai pembuatan produk yang diujikan ke orang lain (problem three analysis).

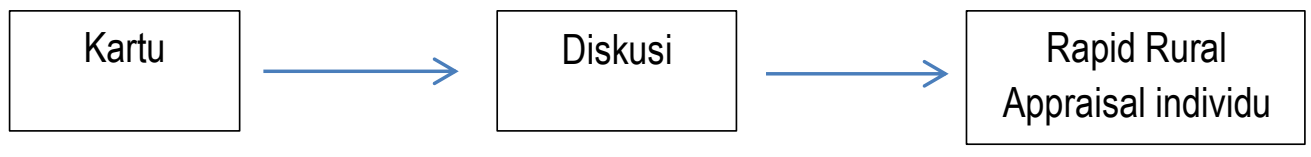

Gambar 2. Model pembelajaran Kardi Pinter siklus pertama 


\section{SIKLUS KEDUA}

Siklus kedua masih menggunakan Kardi Pinter namun bedanya jika pada siklus pertama dilakukan secara individu maka tahap kedua dilakukan satu kelas. Setelah belajar bersama baik di kelas, guru mengajak diskusi dengan kartu di ruang depan koperasi sekolah supaya peserta didik memperoleh suasana lain. Menebak kartu yang cocok dengan jawaban pertanyaan diskusi, memancing diskusi dengan kartu yang bertuliskan istilah-istilah sosiologis adalah tahap kardi. Setelah dilakukan pemantapan materi substansial maka dilakukan Foccused group discussion yang melibatkan masyarakat untuk mengetahui permasalahan pengrajin tahu di desa Donohudan kecamatan Ngemplak Boyolali. Selain harga tahu yang murah yang dikeluhkan pengrajin adalah kelangkaan kayu bakar sebagai sumber energi pengolahan tahu. Maka dari hasil pencarian dari berbagai sumber peserta didik berdiskusi dengan tokoh masyarakat yaitu Kepala desa Donohudan maka dilakukan sebuah inovasi sumber energi terbarukan yang disebut briket ampas tahu. Bahannya terdiri dari ampas tahu, sekam, abu sisa pembakaran, grajen (sisa produksi pengrajin mebel di Donohudan) ditambah tepung maizena dengan cetakan bekas limbah bambu dan menggunakan sinar matahari sebagai pengering briket, telah diuji bisa mengurangi konsumsi kayu bakar pada saat menggoreng tahu.

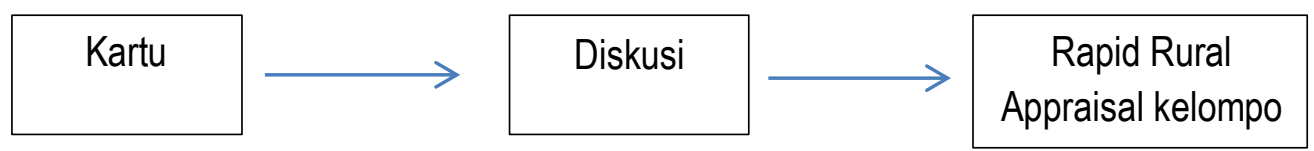

Gambar 3. Model pembelajaran Kardi Pinter siklus kedua

Berikut adalah situasi kelas pada saat pemberian materi substansial kemudian disajikan kartu yang yang bertuliskan istilah-istilah kunci dalam materi penelitian sosial sehingga para peserta didik harus menebak sesuai pengertiannya.

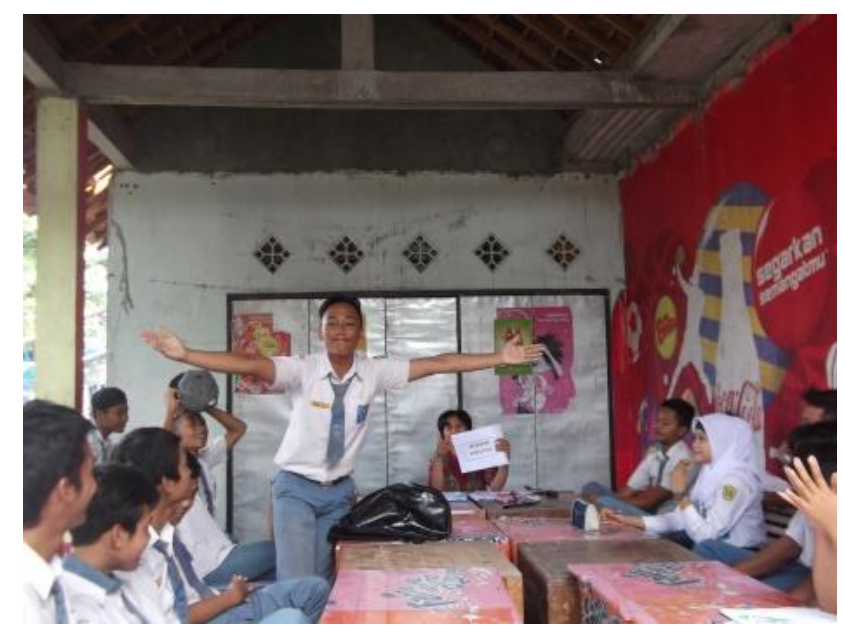

Gambar 4. Suasana kelas di luar ruangan menggunakan tebak kartu materi substansial

Pada gambar 4 menunjukan bahwa ekspresi bahagia peserta didik yang berhasil menebak kartu sesuai dengan istilah materi subtansial. Guru Memberikan apresiasi berupa pujian dan jempol sedangkan siswa yang lain bertepuk tangan. Suasana tersebut membangkitkan kompetisi siswa dalam menebak. 


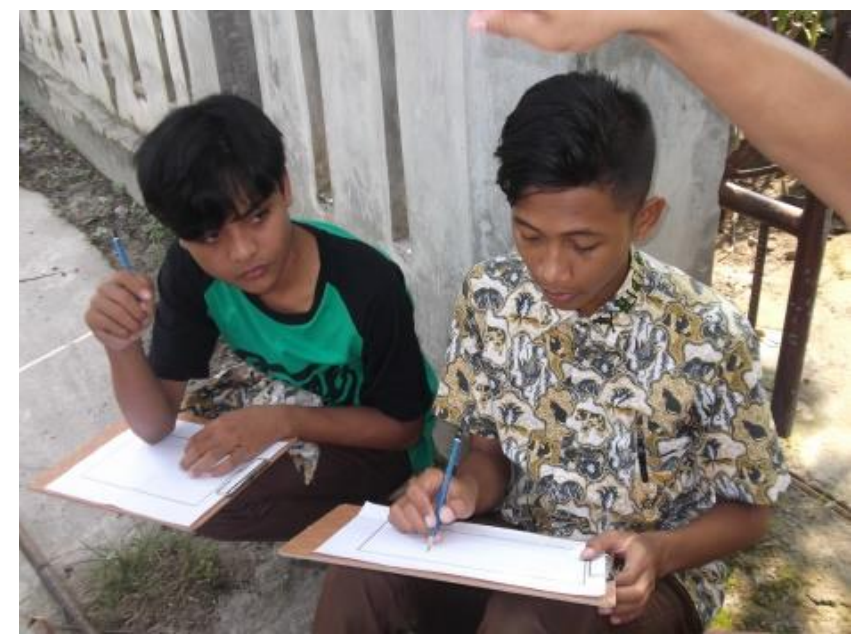

Gambar 5.Siswa melakukan transect dan menggambar social mapping bersama kelompok

Tindak lanjut tugas RRA disajikan langkah-langkah seperti melakukan foccused group discussion bersama masyarakat pengrajin tahu desa Donohudan, memunculkan alternatif pemecahan masalah, membentuk kelompok dan tugas masing-masing peserta didik, membuat produk sebagai hasil inovasi dari sumber energi alternatif, menguji produk dan mempresentasikan hasil produk yang telah diuji kepada masyarakat untuk dicoba apakah memiliki daya guna dan kemudahan ditiru yang pada akhirnya dapat menjadi solusi bagi kelangkaan kayu bakar di kalangan pengrajin tahu Donohudan. Peserta didik membuat laporan dan upload di blog guru mapel sosiologi dan media sosial sebagai usaha publikasi hasil inovasi terhadap masyarakat.

\section{HASIL DAN PEMBAHASAN}

\section{PROFIL SEKOLAH}

SMAN 1 Ngemplak Boyolali beralamatkan di Jl. Embarkasi Haji Desa Donohudan Kecamatan Ngemplak Boyolali. Lokasi gedungnya tepatnya di depan embarkasi haji Desa Donohudan Kecamatan Ngemplak kabupaten Boyolali. Sekolah yang berdiri sejak 6 Desember 1995, tergolong masih muda yaitu 25 tahun usianya. Pada saat dilakukan penelitian jumlah siswa sekitar 1000 terdiri dari 10 rombongan belajar jurusan IPA, 10 rombongan belajar jurusan IPS dan satu rombongan belajar kelas bahasa. Rata-rata peserta didik berasal dari daerah sekitar sekolah, kecamatan Nogosari, kecamatan Giriroto dan sekitarnya yang memiliki taraf pendapatan rata-rata kelas menengah kebawah dengan potensi daerah pertanian sentra pengrajin tahu.

\section{SIKLUS 1}

Hasil penelitian menggunakan Kardi Pinter telah memotivasi peserta didik untuk semangat belajar sosiologi secara berkelompok dengan meningkatkan nilai tertinggi dari 60 ke naik menjadi 80 pada siklus 1 menunjukkan bahwa Kardi Pinter telah mampu meningkatkan pemahaman subtansial materi pelajaran sosiologi di kelas XII C. Nilai rata-rata juga meningkat dari 51,52 setelah menggunakan kardi pinter secara individu menjadi 67,70 dan meningkat pada siklus intervensi kardi pinter berkelompok menjadi 72,41 . Penggunaan kardi pinter membangkitkan semangat berbagi dan peduli lingkungan dengan secara kolaboratif baik dengan teman sekelompok maupun dengan masyarakat desa 
Donohudan terutama para pengrajin tahunya yang dijadikan responden untuk diwawancarai ataukah untuk diskusi dalam rapat yang diadakan dengan kelompok pengrajin tahu dan perangkat desa Donohudan. Jika nikai ketuntasan belajar sosiologi 70 maka sebelum intervensi tidak ada yang tuntas (nilai minimal 30 nilai maksimal 60) setelah menggunakan Kardi Pinter berkelompok hasilnya lebih dari 65\% peserta didik lolos (15 siswa), sedangkan kardi pinter individu pada siklus pertama sekitar 14 siswa kurang lebih $60 \%$ yang tuntas.

Tabel 1. Nilai Posttest

\begin{tabular}{ccc}
\hline Nilai & Kelas Kontrol & Kelas Eksperimen \\
\hline Nilai rata-rata & 67,70 & 72,41 \\
Nilai maksimum & 80 & 89 \\
Nilai minimum & 54 & 50 \\
Standar deviasi & 9,4 & 12,02 \\
& & \\
\hline
\end{tabular}

\section{SIKLUS II}

Hasil penelitian menggunakan Kardi Pinter secara individu ke kelompok hanya sekitar $5 \%$ artinya bahwa hanya ada penambahan satu siswa. Hal ini diakibatkan kompleksitas aktifitas belajar yang dilakukan menggunakan kartu dan diskusi kelas untuk memahami materi pelajaran, untuk pengembangan keterampilan sosial diskusi dan melakukan RRA dengan masyarakat cukup melelahkan dan mungkin terlalu kompleks sehingga perhatian ke materi substansial menjadi berkurang. Sebelum menggunakan Kardi Pinter kelas XII C tidak ada satupun siswa yang mencapai ketuntasan belajar karena nilai minimum 34 nilai maksimum 60 dan nilai rata-rata 51,52 nilai ketuntasan 0\%. Setelah menggunakan Kardi Pinter pada siklus 1 nilai minimum 54 dan maksimum dan meningkat 89 pada siklus II serta rata-rata meningkat menjadi 67,70 , nilai ketuntasan $60 \%$. Sedangkan Kardi Pinter dilakukan secara berkelompok meningkatkan nilai rata - rata siswa sampai 72,42 dan nilai ketuntasan belajar siswa mencapai $65 \%$.

Selain prestasi meningkat dan percaya diri meningkat ada lagi satu hasil belajar dari Kardi Pinter yaitu sebuah produk energi alternatif dari ampas tahu yang dapat mudah dibuat dan ditiru sebagai solusi yang ramah lingkungan pennganti kayu bakar. Briket ampas tahu merupakan produk olah limbah ampas tahu, limbah abu kayu bakar,sekam dan limbah grajin. Briket ampas tahu telah diuji mampu mencapai kadar pembakaran 100 derajad titik didih air. Sehingga mampu menggoreng produk tahu dengan kualitas renyah sama dengan kayu bakar. Kardi pinter mampu meningkatkan prestasi belajar, percaya diri, peduli dan kreaktifitas peserta didik kelas XII C pada mata pelajaran Sosiologi. 


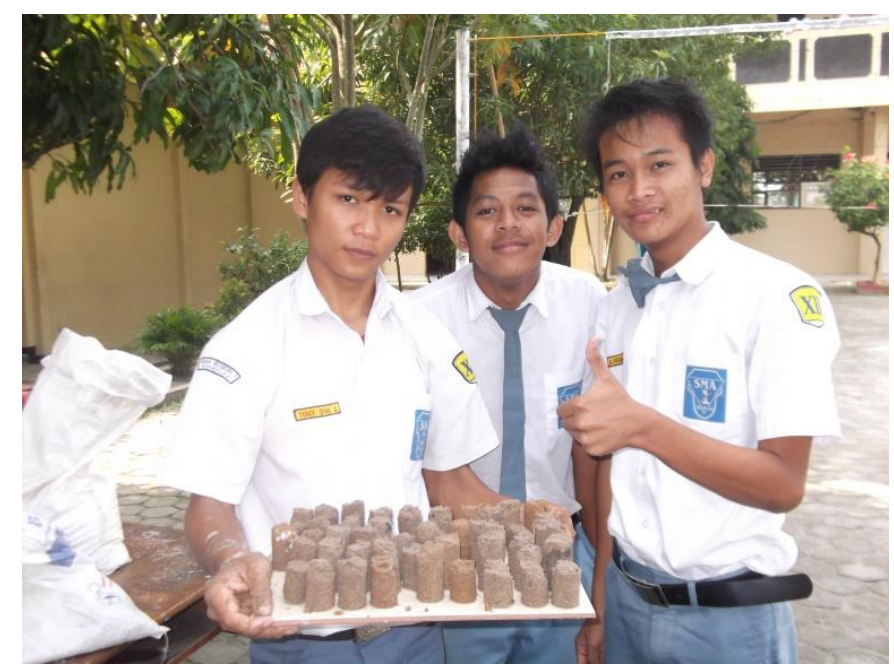

Gambar 6. Peserta didik menampilkan produk briket ampas tahu hasil siklus II

Namun yang perlu digarisbawahi adalah kemampuan kardi pinter untuk meningkatkan prestasi siswa mengalami ketuntasan belajar dari $0 \%$ menjadi $60 \%$ - $65 \%$ sangat ampuh untuk mengatasi rendahnya prestasi belajar kelas XII C yang dianggap "anak buangan" karena dikategorikan paling rendah dibanding kelas dengan kategori $A$ maupun $B$. Peneliti juga mengamati tumbuhnya rasa percaya diri di kalangan siswa untuk mengajak berdiskusi, bertanya dan menegosiasikan ide atau gagasan baik di antara teman-teman sekelas maupun dengan masyarakat pengrajin tahu di desa Donohudan kecamatan Ngemplak. Nilai sikap peduli dan toleransi siklus II yaitu $84 \%$ dan $96,66 \%$ lebih tinggi dari siklus I yaitu $80,49 \%$ dan $93,33 \%$.

\section{KESIMPULAN}

Kardi pinter adalah model pembelajaran aktif dan kolaboratif yang terdiri dari akronim dari kartu, diskusi dan inquiry terbimbing. Inquiry terbimbing menngunakan teknik RRA yang dikenalkan Chambers yaitu transeks,social mapping dan problem three analysis yang dikolaborasi dengan diskusi dan kartu tentang istilah-istilah materi subtansial mata pelajaran sosiologi bab peneitian sosial. Kardi pinter dipilih untuk menjadi solusi peningkatan prestasi peserta didik kelas XII C. Kelas XII C adalah peserta didik yang paling rendah prestasi belajarnya, rendah motivasi belajar, dan sering dihukum karena melakukan tindakan pelanggaran terhadap tata tertib sekolah. Kardi pinter juga berhasil menstimulasi pembuatan produk kreaktif yang merupakan proses recycle dari produk limbah untuk mengatasi kesulitan pengrajin tahu.

Kelebihan kardi pinter adalah mendorong aktif setiap siswa untuk terlibat baik diskusi, bertanya maupun membangkitakan rasa ingin tahu dan mencari apa yang ingin diketahui melalui berbagai sumber media belajar. Selain mendorong aktif juga meningkatkan kemampuan kerjasama dan tingginya kepedulian terhadap sesama dan lingkungan.

Kelemahan kardi pinter adalah model belajar yang kompleks selain subtansi materi peserta didik dikenalkan dengan kondisi lapangan yang menuntut berfikir tingkat tinggi yaitu berfikir kritis untuk dapat mencari solusi dari masalah yang sebenarnya. Kelemahan kardi pinter juga panjangnya waktu yang dilakukan akibat penggunaan teknik RRA seperti transeks, social mapping, dan pohon masalah yang tentu saja kurang efektif jika dilakukan di kelas XII. Namun demikian Kardi Pinter telah terbukti meningkatkan prestasi belajar yang sangat signifikan yaitu mencapai $65 \%$. Sehingga jumlah siswa yang mencapai ketuntasan bertambah. 


\section{SARAN}

Berdasarkan kelemahan kardi pinter sebagai model pembelajaran yang kompleks maka dilakukan lebih dari dua siklus untuk melihat efeknya lebih tajam. Penggabungan kartu dan RRA kurang dapat dibedakan efeknya karena pemahaman materi subtansial atau karena dilakukan bersama-sama. Jika hanya RRA mungkin akan lebih tajam apakah serangkaian pembelajaran lapangan dapat mempertajam pemahaman subtansial.

\section{DAFTAR PUSTAKA}

Tahmidaten, L. (2016). Modul Pembelajaran Sosiologi SMA. Kemdikbud: Malang.

Setiadi, Elly, M \& Kolip, U. (2015). Pengantar Sosiologi. Penerbit Fajar Interpratama mandiri: Jakarta.

Kemdikbud. (2018). Bimbingan Teknis Implementasi Kurikulum 2013.Dirjen Kemdikbud: Jakarta.

Faisal, S. (2015). Penelitian Kualitatif. Yayasan Asih Asah Asuh : Malang.

Yudistira, D. (2015). Menulis Penelitian Tindakan Kelas. Kompas: Gramedia

Johnson, P. D. (2015). Teori Sosiologi Klasik dan Modern 1,2. Kompas: Gramedia, Jakarta.

Aji, M. Q. W. (2019). Mengembangkan Kecakapan Abad 21 Mahasiswa Melalui Model Pembelajaran Inkuiri. Teknodika: Jurnal Penelitian Teknologi Pendidikan, 17 (2), 70 - 84.

Luthfi, A. I., Danial, M. \& Wijaya, M. (2016) . Perbandingan Metode Pemberian Tugas Kerja Kelompok dengan Kerja Individu pada Model Pembelajaran Discovery Learning terhadap Hasil Belajar Peserta Didik Kelas XI MIA SMAN 1 Tondong Tallasa Kab.Pangkep (Studi pada Materi Pokok Termokimia). Jurnal Chemica, 17 (1), 58 - 66.

Wahyuni, S. (2018). Modifikasi Konsep participatory rural appraisal untuk pembekalan kuliah kerja nyata mahasiswa Jawa Barat, Indonesia. Jurnal Ipteks Masyarakat, 7 (1), 38 - 45.

Pebriani, M., Rosnaningish, A. (2018). Pengaruh Model Pembelajaran Kooperatif Tipe Tebak kata terhadap kemampuan menulis bahasa Inggris siswa kelas V SDN Pasar Kemis II Kabupaten Tangerang. Jurnal Humaniora, 2 (2), 49 - 53.

Feriati, F. (2017). Model Pembelajaran Cooperative Learning Tipe Tebak Kata Terhadap Hasil Belajar Siswa Mata Pelajaran Bahasa Arab di MIN Kemu OKU Selatan . JIP: Jurnal IImiah PGM, 3 (2), 123-143.

Kurniwati, D. (2016). Penerapan model pembelajaran inquiry terbimbing dilengkapi LKS untuk meningkatkan keterampian proses sains dan prestasi belajar pada materi pokok hukum dasar kimia siswa Kelas x MIA 4 SMAN 1 Karanganyar Tahun pelajaran 2014/2015. Jurnal Pendidikan Kimia (JPK) UNS, 5 (1), 88-95.

Rismawati, Sinon, I.R.L.S., Yusuf, I., \& Widyaningsih, S. W. (2017). Penerapan Model Pembelajaran Inkuiri Terbimbing (Guided Inquiry)terhadap Keterampilan Proses Sains Peserta Didik di SMK Negeri 02 Manokwari. Lectura: Jurnal Pendidikan, 8 (1), 12 - 25.

How to cite: Noeryanti, A. T. (2020). Meningkatkan hasil belajar sosiologi melalui kardi pinter. Teknodika, 18 (1), 71-79. DOI: https://doi.org/10.20961/teknodika.v18i1.40468 